\title{
Improvement of Flexural Performance of UHPFRC with Hybrid Steel Fiber
}

\author{
Altuğ YAVAŞ ${ }^{1}$ \\ Tamer BIROL ${ }^{2}$ \\ Kaan TÜRKER ${ }^{3}$ \\ Umut HASGÜL ${ }^{4}$ \\ Halit YAZICI ${ }^{5}$
}

\begin{abstract}
This study investigates the flexural behavior of Ultra-High Performance Fiber Reinforced Concrete (UHPFRC) with hybrid steel fiber referencing the ASTM standard C 1609. Two types of end-hooked fibers in macro fiber concretes and one type short straight fiber in micro fiber concretes were used in mono and hybrid forms. In order to determine the flexural response of UHPFRC, a series of prismatic beam specimens with a dimension of $100 \times 100 \times 400 \mathrm{~mm}$ were tested under the four-point loading and following parameters were compared and discussed in terms of the first cracking load and pattern, flexural strength, deflection capacity, toughness and residual strength capacity under bending loads. The test results showed that as the fiber amount of specimens with the mono fiber increases, in general, better flexural behavior may be ensured. It should be also noted that the hybrid use enhanced the flexural behavior compared to the macro fiber usage.
\end{abstract}

Keywords: Ultra-high performance fiber reinforced concrete, hybrid fiber, steel fiber, flexural behaviour.

Note:

- This paper has been received on November 20, 2018 and accepted for publication by the Editorial Board on December 4, 2019.

- Discussions on this paper will be accepted by January 31, 2021.

- https://doi.org/10.18400/tekderg.485565

1 Balikesir University, Department of Civil Engineering, Balıkesir, Turkey - ayavas@balikesir.edu.tr https://orcid.org/0000-0002-2619-8671

2 Balikesir University, Department of Civil Engineering, Balıkesir, Turkey - tbirol@balikesir.edu.tr https://orcid.org/0000-0003-2428-6202

3 Balikesir University, Department of Civil Engineering, Balıkesir, Turkey - kturker@balikesir.edu.tr https://orcid.org/0000-0002-3106-4627

4 Balikesir University, Department of Civil Engineering, Balıkesir, Turkey - hasgul@balikesir.edu.tr https://orcid.org/0000-0002-9358-3369

5 Dokuz Eylul University, Department of Civil Engineering, İzmir, Turkey - halit.yazici@deu.edu.tr https://orcid.org/0000-0002-0921-9709 


\section{INTRODUCTION}

Over the last two decades, the production of Ultra-High Performance Concrete (UHPC) has become possible with new developments in concrete technology. This concrete is produced with high density matrix, very low water/binder ratio and special treatments such as curing under heat/pressure. Though these types of special concretes possess high compressive strength, their behavior is more brittle [1-3]. In order to decrease brittleness and to ensure high amount of energy absorption and ductility as well as bearing capacity for these types of special concretes, steel fibers are added to the concrete mixture. This type of concrete is widely known as the Ultra-High Performance Fiber Reinforced Concrete (UHPFRC) [4]. The UHPFRC has various advantages over conventional concrete and fiber reinforced concrete such as higher durability, ductility and strength because of its low porosity, dense matrix, high tensile/compressive strength and ductile tensile behavior [5]. This kind of concrete responds very high durability through the high density and crack-bridging of steel fibers. Thus, this material is classified as the Ultra-High Performance Fiber Reinforced Concrete (UHPFRC) or High Performance Fiber Reinforced Cement Composite (HPFRCC).

The UHPFRC doesn't have a widespread use due to its difficult and high cost production. For this reason, low cost and easily producible UHPFRC studies (with ordinary raw materials, standard curing conditions and mixers) have gained momentum in the recent years and successful results have been achieved [4, 6-12]. Therefore, it has become possible and widespread to use the UHPFRC in conventional reinforced concrete construction.

Even though several studies were carried out, there is no authority or standard to classify the term "high performance". However, some conditions for this classification, such as the uniaxial compressive strength and pseudo strain-hardening under tension or bending, are expected to be improved in some way [13-16]. The pseudo strain-hardening response can be ensured with a good amount of fiber content. However, insufficient fiber volume fraction and/or low concrete compressive strength may lead to softening response under tension or bending types of loading [17].

Almost all fibrous concretes used commercially today involve the use of a single fiber type. Clearly, a given type of fiber can only be effective in a limited range of crack opening and deflection. In order to improve the performance of UHPFRC, one of the promising methods is to blend together two or more steel fiber types in a matrix since the micro and macro steel fibers play a role at two different levels depending on the length and diameter of fibers. In hybrid fiber reinforced concrete, the micro fibers improve the strength and stiffness in the pre-peak region since crack widths are still small. The macro fibers limit the formation of wide (major) cracks occurring at the point where a single crack widens due to crack localization. The micro fibers also improve pull-out response of the macro fibers and thereby produce composites with high strength and toughness [5, 18-21].

The inclusion of steel fibers at high dosages has potential disadvantages due to poor workability and increased cost. The cost of steel fiber of $1.0 \%$ by volume applied in the UHPFRC is generally higher than that of matrix. Hence, it is important to minimize the fiber amount without sacrificing the superior performance of UHPFRC [5]. Taking into account the cost/performance ratio for this kind of material, it is necessary to optimize its industrial use. 
In recent studies regarding the impact of hybrid fiber use to mechanical properties of the UHPFRC, different sized steel fibers [5, 18-25] and usage of both steel and synthetic fibers $[2,26-32]$ were combined in the concrete mixtures. It can be summarized from these studies that hybrid fiber use leads to an increase in the energy absorption capacity and it improves the cracking response in comparison to mono fibers. Thus, new research on the impact of different configurations are needed in order for them to be used in the UHPFRC matrix.

The primary objective of this study is to investigate the flexural behavior of UHPFRC with hybrid steel fiber content and to compare it with the mono form. Another purpose of the study is to produce the UHPFRC under standard curing conditions and with standard mixers. In the hybrid mixtures, the high-strength micro steel fiber which is commonly used in UHPFRCs, and two types of macro steel fibers which have lower strength and cost (almost half of the micro fiber in cost), were used together. In the research study, various prismatic beam specimens, which have different fiber volume fractions in the mono as well as the hybrid forms, were produced and tested under the four-point loading in conformity with the ASTM standard C 1609 [33]. Test parameters including the first cracking load, cracking pattern, flexural strength, deflection capacity, toughness values and residual strength capacity were discussed on the mono and hybrid fiber specimens. In addition, the compressive strengths and elastic modulus (young's modulus) values of cubic and cylinder samples were determined for different fiber configurations.

\section{EXPERIMENTAL STUDY}

\subsection{Material and Specimen Preparation}

The cement $(C)$ used in this study was Portland cement CEM I 42.5 R. However, two different types of supplementary cementitious materials were used, the names of which are well-known ground granulated blast-furnace slag $(G G B S)$ and silica fume $(S F)$. The chemical and physical properties of the $C, G G B S$ and $S F$ are presented in Table 1. Two sizes of quartz sand, the particle sizes in the range of 0 to $0.8 \mathrm{~mm}(Q S 1)$ and 1.0 to $3.0 \mathrm{~mm}(Q S 2)$, were chosen as aggregate. The gradings and cumulative curves for each aggregate and the total mixture are given in Figure 1. The specific gravities of $0-0.8 \mathrm{~mm}$ and $0-3 \mathrm{~mm}$ quartz sands were respectively $2.68 \mathrm{~g} / \mathrm{cm}^{3}$ and $2.66 \mathrm{~g} / \mathrm{cm}^{3}$. A polycarboxylate ether-based superplasticizer $(S P)$ with the density of $1.08-1.14 \mathrm{~kg} /$ litre was used to ensure good workability. The final proportions for each fiber volume fraction and the fresh state properties of UHPFRC mixtures are summarized in Table 2.

In the study, two types of end-hooked steel fibers (aspect ratios: 30/0.55 and 60/0.75) in the macro mixtures and one type short straight steel fiber (aspect ratio: 13/0.16) in the micro mixtures were considered for the mono and hybrid forms. The brass coated high-strength steel having a smooth surface was used for the micro-sized fibers. However, the macro fibers have end-hooked geometry to improve the interfacial bond stress between the steel fiber and cementitious matrix. In addition, the macro fibers are cheaper and have longer bond length, but have lower tensile strength compared to the micro-sized fibers.

A standard pan mixer with a 90 litre capacity was used to prepare the test specimens. The $C$, $G G B S, S F$ and $Q S$ s were mixed for about 3 minutes. Water and half of the $S P$ were added into the mixture and mixed for another 5 minutes. Then the rest of $S P$ was added and mixed 
for additional 5 minutes. Later on, the fibers were dispersed carefully into the mixture and mixed until homogenously distributed.

Table 1 - Chemical composition of cementitious materials

\begin{tabular}{cccc}
\hline Composition (\%) & C & SF & GGBS \\
\hline $\mathrm{SiO}_{2}$ & 19.80 & $90-93$ & 41.49 \\
$\mathrm{Al}_{2} \mathrm{O}_{3}$ & 5.47 & $0.4-0.9$ & 16.34 \\
$\mathrm{Fe}_{2} \mathrm{O}_{3}$ & 3.46 & $1.0-2.0$ & 0.61 \\
$\mathrm{CaO}$ & 64.44 & $0.2-0.7$ & 29.26 \\
$\mathrm{MgO}$ & 1.30 & $0.9-1.3$ & 7.68 \\
$\mathrm{SO}_{3}$ & 2.67 & - & 1.90 \\
$\mathrm{Na}_{2} \mathrm{O}$ & 0.40 & $0.2-0.6$ & 0.80 \\
$\mathrm{~K}_{2} \mathrm{O}$ & 0.67 & $1.0-1.3$ & 1.10 \\
$\mathrm{Cl}$ & 0.012 & - & 0.01 \\
$\mathrm{Fe}_{2} \mathrm{O}_{3}$ & - & $1.0-2.0$ & - \\
Specific surface $\left(\mathrm{m}^{2} / \mathrm{kg}\right)$ & 380 & 20000 & - \\
Density $\left(\mathrm{g} / \mathrm{cm}^{3}\right)$ & 3.13 & 2.10 & - \\
\hline
\end{tabular}
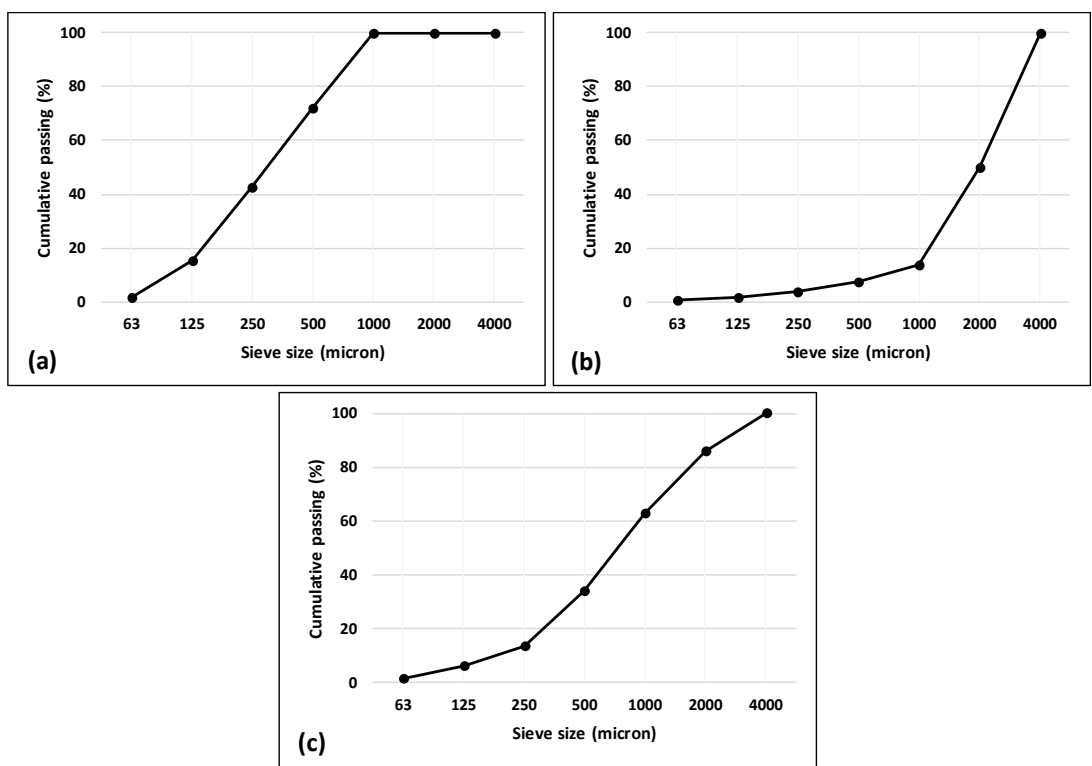

Fig. 1 - The grading and cumulative curve for the aggregates; a) QS1, b) QS2, c) mix

The prismatic beam specimens corresponding to total of 18 mixtures were produced to study the effect of different fiber contents. As summarized in Table 3, nine of the configurations 
consist of the mono form while eight of them are in the hybrid form. The remaining one is the reference specimen without the steel fiber to see the contribution of the fiber content.

Table 2 - Mixture proportions of the UHPFRC by weight $\left(\mathrm{kg} / \mathrm{m}^{3}\right)$ and fresh state properties

\begin{tabular}{|c|c|c|c|c|c|c|c|c|c|c|}
\hline & Fiber content & $C$ & $S F$ & $G G B S$ & QS1 & QS2 & Water & $S P$ & $\begin{array}{l}\text { Slump } \\
\text { flow } \\
(\mathbf{m m})\end{array}$ & $\begin{array}{r}t_{500} \\
\text { (sn) }\end{array}$ \\
\hline & Reference & 690 & 138 & 276 & 542 & 542 & 199 & 17.25 & 900 & 2.1 \\
\hline \multirow{3}{*}{ 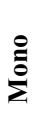 } & $13(1.0)$ & \multirow{3}{*}{690} & \multirow{3}{*}{138} & \multirow{3}{*}{276} & \multirow{3}{*}{530} & \multirow{3}{*}{530} & \multirow{3}{*}{199} & \multirow{3}{*}{17.25} & 780 & 2.7 \\
\hline & $30(1.0)$ & & & & & & & & 805 & 3.1 \\
\hline & $60(1.0)$ & & & & & & & & 840 & 3.3 \\
\hline \multirow{3}{*}{$\stackrel{\ominus}{\stackrel{\Xi}{g}}$} & $13(1.5)$ & \multirow{3}{*}{690} & \multirow{3}{*}{138} & \multirow{3}{*}{276} & \multirow{3}{*}{525} & \multirow{3}{*}{525} & \multirow{3}{*}{199} & \multirow{3}{*}{17.25} & 760 & 3.2 \\
\hline & $30(1.5)$ & & & & & & & & 775 & 3.2 \\
\hline & $60(1.5)$ & & & & & & & & 800 & 3.5 \\
\hline \multirow{4}{*}{ 를 } & $13(0.5) 30(1.0)$ & \multirow{4}{*}{690} & \multirow{4}{*}{138} & \multirow{4}{*}{276} & \multirow{4}{*}{525} & \multirow{4}{*}{525} & \multirow{4}{*}{199} & \multirow{4}{*}{17.25} & 771 & 3.3 \\
\hline & $13(1.0) 30(0.5)$ & & & & & & & & 767 & 3.2 \\
\hline & $13(0.5) 60(1.0)$ & & & & & & & & 780 & 3.4 \\
\hline & $13(1.0) 60(0.5)$ & & & & & & & & 773 & 3.2 \\
\hline \multirow{3}{*}{$\stackrel{\varrho}{\stackrel{\Xi}{\Sigma}}$} & $13(2.0)$ & \multirow{3}{*}{690} & \multirow{3}{*}{138} & \multirow{3}{*}{276} & \multirow{3}{*}{520} & \multirow{3}{*}{520} & \multirow{3}{*}{199} & \multirow{3}{*}{17.25} & 750 & 4.1 \\
\hline & $30(2.0)$ & & & & & & & & 755 & 3.9 \\
\hline & $60(2.0)$ & & & & & & & & 770 & 3.4 \\
\hline \multirow{4}{*}{ 릏 } & $13(1.0) 30(1.0)$ & \multirow{4}{*}{690} & & & & & & & 755 & 3.9 \\
\hline & $13(1.5) 30(0.5)$ & & 138 & 276 & 520 & 520 & 109 & 1725 & 758 & 4.0 \\
\hline & $13(1.0) 60(1.0)$ & & 138 & 210 & 520 & 520 & 199 & 17.25 & 751 & 3.8 \\
\hline & $13(1.5) 60(0.5)$ & & & & & & & & 753 & 4.0 \\
\hline
\end{tabular}

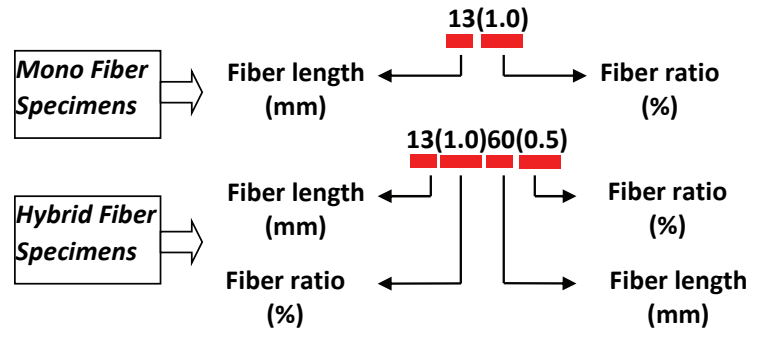

Fig. 2 - Specimen notations

The fiber volume fractions of 1.0, 1.5 and $2.0 \%$ were chosen to obtain deflection hardening behavior as well as ensure good workability. In the study, the specimen definitions were classified in terms of the considered fiber types and volume fractions. The notations of test 
specimens indicating the mono and hybrid forms are shown in Figure 2. For example, 13(1.0) denotes the test specimen including the micro steel fiber of $13 \mathrm{~mm}$ with $1 \%$ by volume in the mono form, while the 13(1.0)60(0.5) shows the hybrid specimen containing the micro fiber of $13 \mathrm{~mm}$ ( $1 \%$ by volume) and the macro fiber of $60 \mathrm{~mm}(0.5 \%$ by volume).

For each mixture, six cubic samples with size of $100 \mathrm{~mm}$, two cylinder samples with $100 \mathrm{~mm}$ diameter by $200 \mathrm{~mm}$ height as well as three prismatic beams with a square section of 100 $\mathrm{mm} \times 100 \mathrm{~mm}$ and length of $400 \mathrm{~mm}$ were casted as shown in Figure 3a. The mixture was placed into the prismatic molds from one end to other by means of a plastic bucket. During the placement process, no vibration was conducted to prevent fiber gravitation. In the study, a more workable UHPFRC mixture was produced than those of presented in the previous studies [6-9]. As shown in Table 2, the slump flow value for the non-fiber mixture was measured as $900 \mathrm{~mm}$. However, this value for the micro, macro and hybrid mixtures were measured in the range of 750 to $780 \mathrm{~mm}, 770$ to 850 and 760 to $840 \mathrm{~mm}$, respectively.

Table 3 - Fiber contents, compressive strengths and elastic modulus of the specimens

\begin{tabular}{|c|c|c|c|c|c|c|}
\hline \multirow{2}{*}{$\begin{array}{c}\text { Fiber } \\
\text { content }\end{array}$} & \multirow{2}{*}{ Specimen } & \multicolumn{3}{|c|}{ Fiber volume content $(\%)$} & \multirow{2}{*}{$\begin{array}{c}\text { Compressive } \\
\text { strength } \\
\text { (MPa) }\end{array}$} & \multirow{2}{*}{$\begin{array}{c}\text { Elastic } \\
\text { modulus } \\
(\text { GPa) }\end{array}$} \\
\hline & & $13 / 0.16$ & $30 / 0.55$ & $60 / 0.75$ & & \\
\hline Non-fiber & Reference & - & - & - & 90 & 38 \\
\hline \multirow{9}{*}{$\begin{array}{l}\text { Mono fiber } \\
\text { specimens }\end{array}$} & $13(1.0)$ & 1.0 & - & - & 120 & 42 \\
\hline & $13(1.5)$ & 1.5 & - & - & 134 & 45 \\
\hline & $13(2.0)$ & 2.0 & - & - & 132 & 42 \\
\hline & $30(1.0)$ & - & 1.0 & - & 117 & 45 \\
\hline & $30(1.5)$ & - & 1.5 & - & 121 & 42 \\
\hline & $30(2.0)$ & - & 2.0 & - & 114 & 41 \\
\hline & $60(1.0)$ & - & - & 1.0 & 114 & 40 \\
\hline & $60(1.5)$ & - & - & 1.5 & 121 & 42 \\
\hline & $60(2.0)$ & - & - & 2.0 & 119 & 44 \\
\hline \multirow{8}{*}{$\begin{array}{l}\text { Hybrid fiber } \\
\text { specimens }\end{array}$} & $13(0.5) 30(1.0)$ & 0.5 & 1.0 & - & 121 & 45 \\
\hline & $13(1.0) 30(0.5)$ & 1.0 & 0.5 & - & 114 & 44 \\
\hline & $13(1.0) 30(1.0)$ & 1.0 & 1.0 & - & 128 & 45 \\
\hline & $13(1.5) 30(0.5)$ & 1.5 & 0.5 & - & 132 & 41 \\
\hline & $13(0.5) 60(1.0)$ & 0.5 & - & 1.0 & 114 & 40 \\
\hline & $13(1.0) 60(0.5)$ & 1.0 & - & 0.5 & 123 & 43 \\
\hline & $13(1.0) 60(1.0)$ & 1.0 & - & 1.0 & 129 & 41 \\
\hline & $13(1.5) 60(0.5)$ & 1.5 & - & 0.5 & 136 & 43 \\
\hline
\end{tabular}

The slump-flow tests showed that the fiber content (amount and type) had a significant effect on the flow ability of UHPFRC (Table 2). As the fiber amount increases, the spread values decrease for all fiber types. For the mono form, the spread values obtained for the macro fibers were greater than the micro fiber use. Although there was no significant trend in the 
hybrid form, the spread values showed a decreasing trend with increasing fiber amount. It was seen from the $t_{500}$ values that the viscosity of concrete increased with respect to the mono form as a result of multiple fiber use in the mixture (Table 2).

After casting, the specimens were covered by plastic sheets and stored at room temperature. Twenty-four hours later, the specimens were taken out of their molds and stored in a water tank at approximately $20^{\circ} \mathrm{C}$ until the test day. All specimens were tested at 28 days.

For each prepared mixture, the cubic and cylinder samples were tested separately to measure the compressive strength and elastic modulus, respectively. The compression tests were conducted by a testing machine with a maximum load capacity of $3000 \mathrm{kN}$. In addition, the values of elastic modulus were determined using a compressometer which measures the average compressive strain of two linear voltage differential transformers (LVDTs) as shown in Figure 3b. The average compressive strengths and elastic moduli corresponding to the nonfiber, mono and hybrid fiber specimens are given in Table 3.

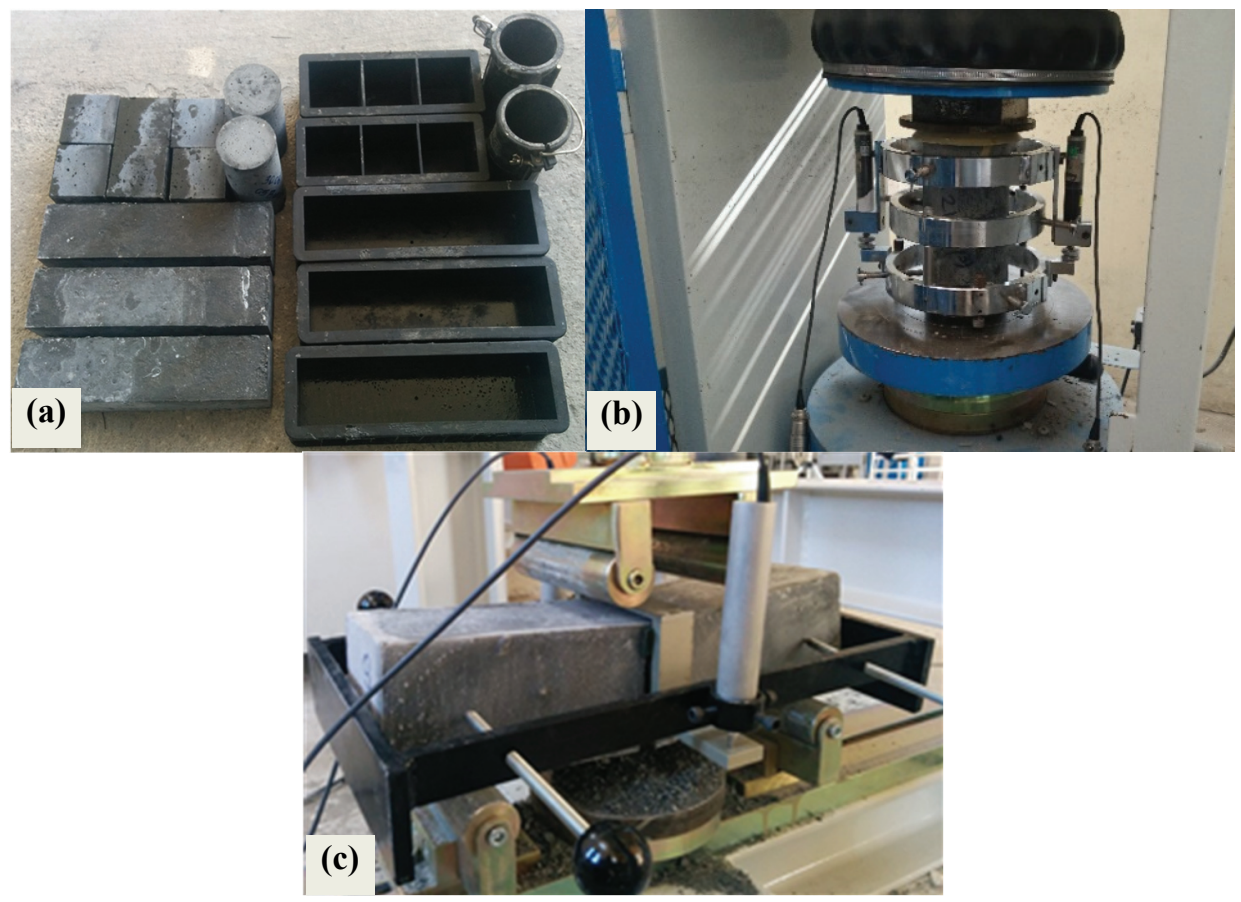

Fig. 3 - Test specimens and set-ups;

a) test specimens, b) compression test set-up and c) flexural test set-up

\subsubsection{Flexural test}

The flexural behavior of fiber reinforced concretes has two distinctive regions, which consist of the deflection hardening and softening behaviors depending on load carrying capacity after 
first cracking [5]. Figure 4 illustrates a sample load-deflection curves denoting all calculation parameters. Referring to Figure 4, the peak load $\left(P_{p}\right)$ is greater than the first-peak load $\left(P_{1}\right)$ in the deflection hardening behavior whereas both the peak loads are at the same point for the softening behavior. The first-peak load is defined as the value of load corresponding to the first point on the load-deflection curve where the slope is zero. The peak load is defined as the maximum value obtained prior to reaching the end-point deflection on the loaddeflection curve. Thus, the peak and first-peak strength values can be calculated by the formula (Equation 1) for modulus of rupture in ASTM C 1609 [33]:

$f=\frac{P L}{b d^{2}}$

where $f$ denotes the strength, $P$ is the load; $b, d$ and $L$ are the width, depth and length of specimen, respectively.

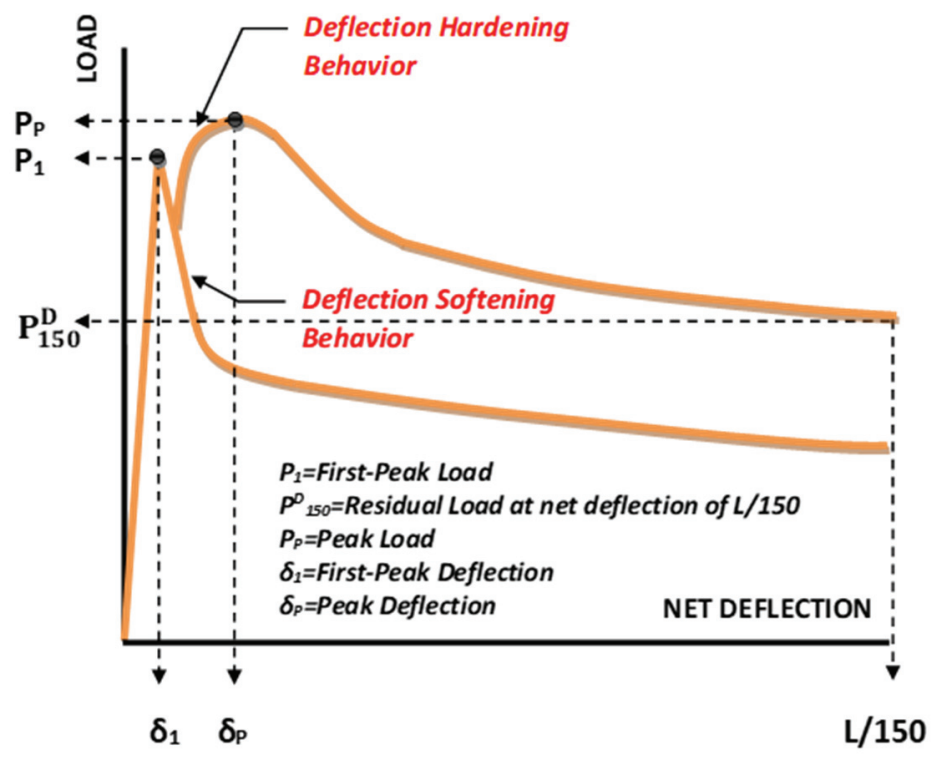

Fig 4 - Calculation parameters on a sample load-deflection curve [33]

The deflection limit of $L / 150$ is based on calculation of the energy dissipation capacity (toughness) related to the total area under the load-deflection curve, as shown in Figure 4. The peak load deflection $\left(\delta_{P}\right)$ is the net deflection value, measured at the mid-span of beam specimen, corresponding to the peak load on the load-deflection curve.

The flexural tests were conducted under four-point loading on the simply supported beam specimens with a clear span of $300 \mathrm{~mm}$, according to the ASTM C 1609 [33], as shown in Figure $3 \mathrm{c}$. Three beams were considered to determine the flexural behavior of each mixture. The test was conducted on a servo hydraulic testing machine having a capacity of $200 \mathrm{kN}$. The test machine is controlled by displacement during the whole process to obtain the load 
versus deflection behavior. The speed of applied displacement increments throughout the entire test program was $0.1 \mathrm{~mm} / \mathrm{min}$. The load was divided into two equal loads, providing a distance of $100 \mathrm{~mm}$ between them through a spreader beam. Later, the load was measured with a load cell which was placed between the cross head and spreader beam. To obtain the average mid-span deflection, two LVDTs were attached on the both sides of specimen with the help of a steel frame excluding the beam settlements at the supports. The applied loads and mid-span deflections were recorded through the data acquisition system during the test procedure. The detailed test procedure can be found in the ASTM C 1609.

In order to minimize the influence of non-uniform fiber distribution, the top or the bottom surface of the specimen was rotated to the side in order to take measures prior to the bending test. Note that all specimens showed uniform fiber distribution.

\section{RESULTS}

\subsection{Compressive Strength and Elastic Modulus}

Test results of average compressive strengths and elastic modulus values are presented in Table 3. Here, the compressive strength values were obtained from the cubic samples and the elastic moduli were obtained from the cylinder samples. The results showed that macro fiber use increased the compressive strength by an average of $31 \%$ compared to the non-fiber mixture. Similarly, use of micro and hybrid fiber increased the compressive strength by $43 \%$ and $39 \%$, respectively. Regardless of the fiber content, it is apparent that the compressive strengths for both the mono and hybrid forms are much greater than that of the non-fiber mixture, as would be expected. It was also noted that use of micro fiber was more impactful to the relation between macro fibers and compressive strength. Although the compressive strength tends to increase as the volumetric fraction changes from $1.0 \%$ to $1.5 \%$, when the fiber fraction increases further, such as from $1.5 \%$ to $2.0 \%$, the compressive strength may decrease somewhat. But, this deduction for the hybrid fiber samples is distinctive since the average compressive strength showed increasing tendency when all amount of the fibers were considered (Table 3 ). The test results on cylinder samples also showed that the fiber content has no significant effect on the elastic modulus so that the average elastic modulus for all specimens containing the steel fiber were determined as about $42.6 \mathrm{GPa}$.

\subsection{Flexural Behavior}

In the study, three beam specimens corresponding to each fiber configuration were tested under the four-point loading and their load-midspan deflection behavior was obtained. The intermediate one among the three responses in terms of the flexural strength and toughness was chosen for the purpose of comparisons and evaluations [34]. The standard deviations related to these quantities for each fiber type considering three specimens and the characteristic values for the intermediate specimens are summarized in Table 4. For each volume fraction, the load versus midspan deflection responses corresponding to the selected specimens having the mono fiber forms are shown in Figures 5a-5c. 

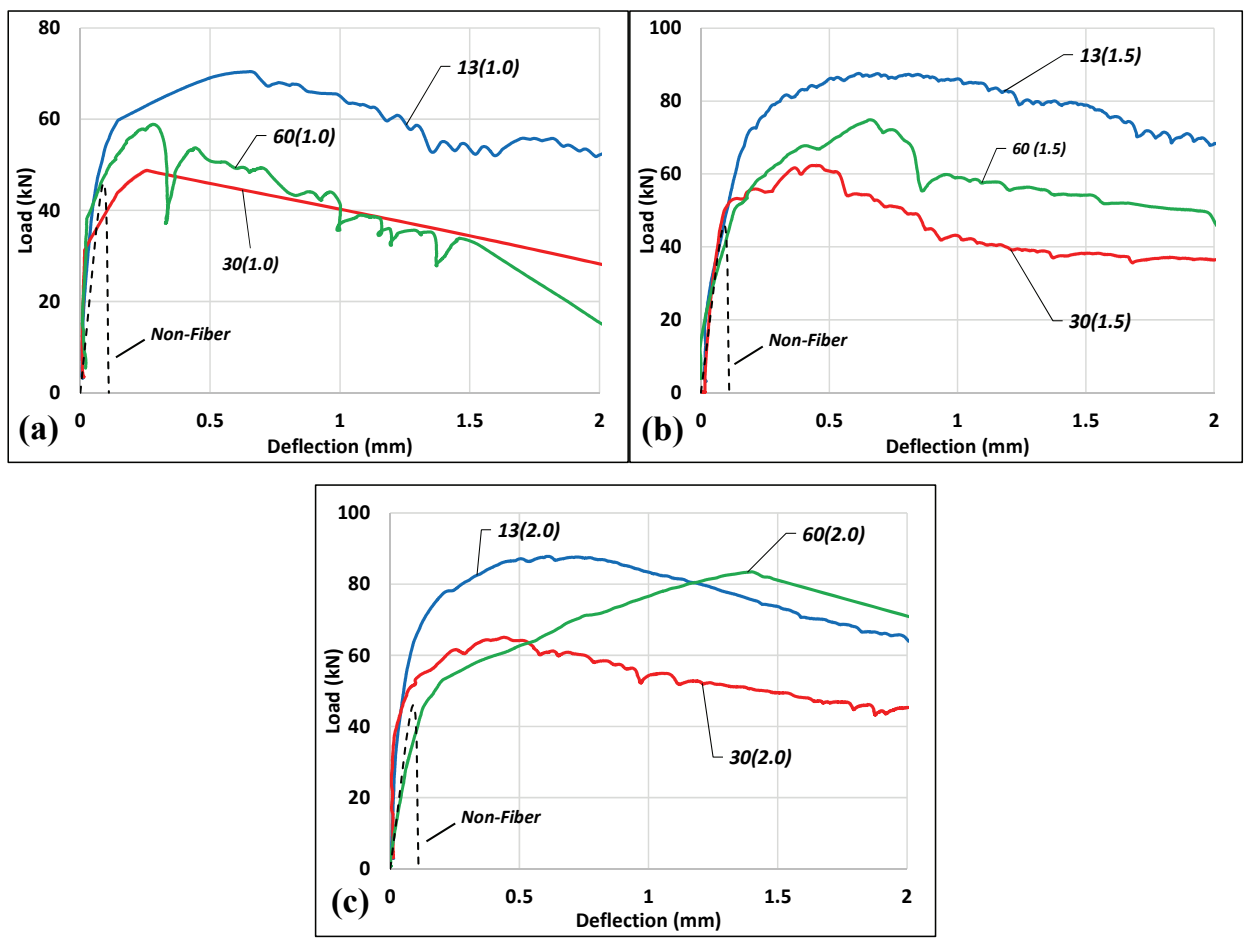

Fig. 5 - Load-deflection curves of UHPFRC specimens with mono steel fiber;

a) $1.0 \%$ volumetric fraction, b) $1.5 \%$ volumetric fraction, c) $2.0 \%$ volumetric fraction

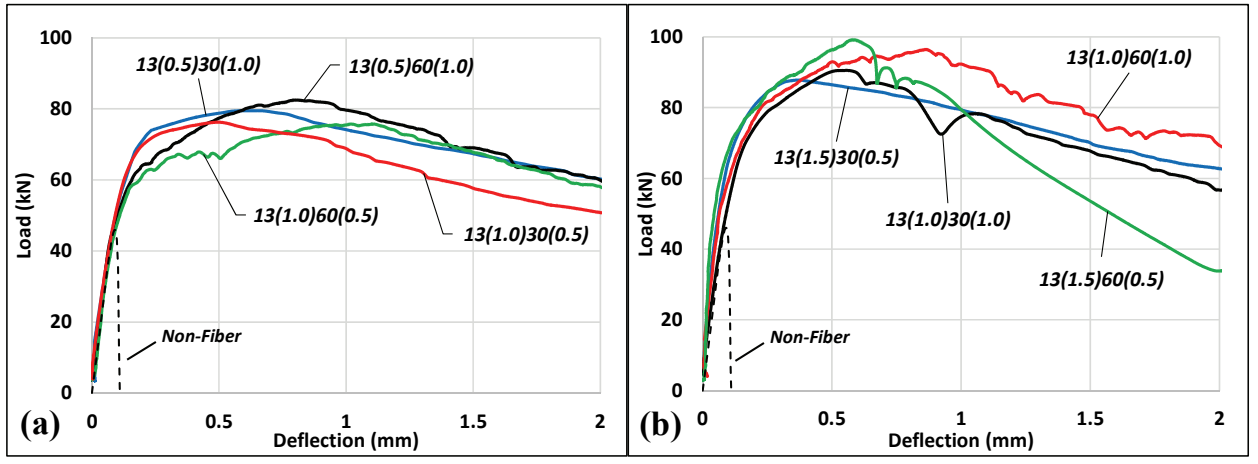

Fig. 6 - Load-deflection curves of UHPFRC specimens with hybrid steel fiber;

a) $1.5 \%$ volumetric fraction, b) $2.0 \%$ volumetric fraction

It is apparent from Figures 5a-5c that use of mono fiber provided significant gain in strength and deflection hardening capacity. These parameters show an increasing trend when the volume fraction goes up from $1.0 \%$ to $1.5 \%$. It was also noted that as the fiber amount 
increases further, up to $2.0 \%$ by volume, the performances of specimens with micro fiber remains limited as shown in Figure 5a-5c. However, the test specimens with the macro fiber sustained their increasing trend.

As shown from the load-deflection responses with the hybrid fiber (Figures 6a-6b), a small increment in the fiber volume fraction from $1.5 \%$ to $2.0 \%$ may lead to an increase in the strength and toughness capacities of the specimens.

Table 4 - The parameters related to flexural strength of specimens

\begin{tabular}{lcccccccc}
\hline Notation & $\begin{array}{c}\boldsymbol{P}_{\mathbf{1}} \\
(\mathbf{k N})\end{array}$ & $\begin{array}{c}\boldsymbol{P}_{\boldsymbol{P}} \\
(\mathbf{k N})\end{array}$ & $\begin{array}{c}\boldsymbol{\delta}_{\boldsymbol{P}} \\
(\mathbf{m m})\end{array}$ & $\boldsymbol{P}^{\boldsymbol{D}_{150} / \boldsymbol{P}_{\boldsymbol{p}}}$ & $\begin{array}{c}\boldsymbol{f}_{\boldsymbol{P}} \\
(\mathbf{M P a})\end{array}$ & $\begin{array}{c}\boldsymbol{T} \\
(\mathbf{k N m m})\end{array}$ & $\begin{array}{c}\text { Standard deviation for } \\
\text { three responses }\end{array}$ \\
\hline Reference & - & 45.98 & 0.06 & - & 13.29 & 2.1 & 1.51 & - \\
\hline $13(1.0)$ & 15.8 & 70.47 & 0.66 & 0.74 & 21.14 & 122 & 0.27 & 6.03 \\
$13(1.5)$ & 27.0 & 87.58 & 0.61 & 0.78 & 26.27 & 159 & 2.94 & 16.46 \\
$13(2.0)$ & 26.8 & 87.81 & 0.61 & 0.73 & 26.34 & 148 & 2.80 & 17.62 \\
\hline $30(1.0)$ & $*$ & 48.78 & 0.26 & 0.58 & 14.63 & 76 & 1.51 & 8.62 \\
$30(1.5)$ & 25.0 & 62.33 & 0.46 & 0.58 & 18.70 & 93 & 1.57 & 3.51 \\
30(2.0) & $*$ & 65.05 & 0.44 & 0.70 & 19.52 & 109 & 2.36 & 16.17 \\
\hline $60(1.0)$ & $*$ & 58.88 & 0.28 & 0.26 & 17.66 & 85 & 0.83 & 2.52 \\
60(1.5) & 23.2 & 74.88 & 0.66 & 0.63 & 22.46 & 118 & 2.77 & 14.05 \\
60(2.0) & 28.0 & 83.45 & 1.40 & 0.85 & 25.04 & 138 & 2.82 & 15.87 \\
\hline $13(0.5) 30(1.0)$ & 26.0 & 74.49 & 0.65 & 0.81 & 22.35 & 127 & 2.31 & 13.20 \\
$13(1.0) 30(0.5)$ & 24.8 & 76.24 & 0.50 & 0.67 & 22.87 & 127 & 0.79 & 17.35 \\
$13(1.0) 30(1.0)$ & 25.4 & 90.51 & 0.56 & 0.63 & 27.15 & 146 & 1.83 & 2.08 \\
$13(1.5) 30(0.5)$ & 23.5 & 87.78 & 0.37 & 0.71 & 26.33 & 179 & 1.89 & 15.10 \\
\hline $13(0.5) 60(1.0)$ & 24.0 & 82.74 & 0.80 & 0.73 & 24.74 & 142 & 2.52 & 14.64 \\
$13(1.0) 60(0.5)$ & 25.5 & 75.72 & 1.02 & 0.77 & 22.72 & 133 & 2.76 & 17.90 \\
$13(1.0) 60(1.0)$ & 21.3 & 96.42 & 0.86 & 0.72 & 28.39 & 168 & 2.39 & 14.19 \\
$13(1.5) 60(0.5)$ & $*$ & 99.15 & 0.58 & 0.34 & 29.75 & 163 & 2.09 & 17.79 \\
\hline$*:$ Could not be determined & & & & & & & \\
\hline & & & & & & & &
\end{tabular}

\subsubsection{First Cracking Load and Cracking Pattern}

The first cracking loads $\left(P_{1}\right)$ related to the test specimens were determined from the loaddeflection curves. In this way, the specific point where the initial stiffness of curve changes, was taken as the cracking point. It is interesting to note that whereas this point was directly captured for many specimens, some load-deflection curves did not show this point distinctly. The numerical results regarding to the first cracking loads are summarized in Table 4.

- The first cracking loads of specimens with micro fiber, as expected, were higher than those of the macro fiber specimens, because the crack widths were very small prior to the peak load. 
- The cracking response of the hybrid specimens could differ depending on the amount of micro and macro fibers considered in the mixture. The hybrid specimens containing the macro fibers of $30 \mathrm{~mm}$ showed better performance than that of the $60 \mathrm{~mm}$ macro fibers, in terms of the first cracking load. The greatest value for this parameter was obtained when the steel fiber content was increased to $2.0 \%$ by volume.

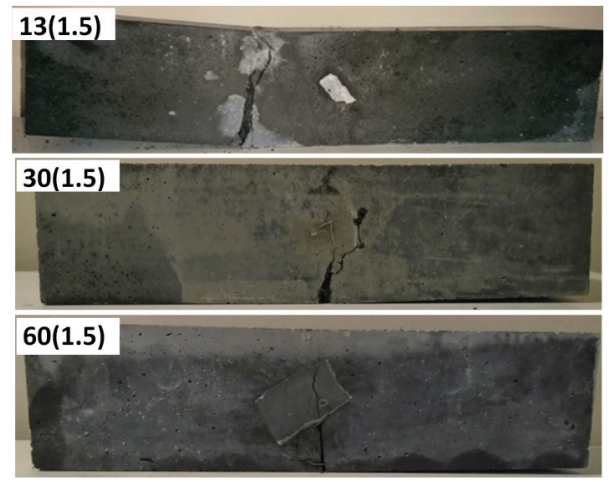

Fig. 7 - Cracking patterns of UHPFRC specimens with mono steel fiber

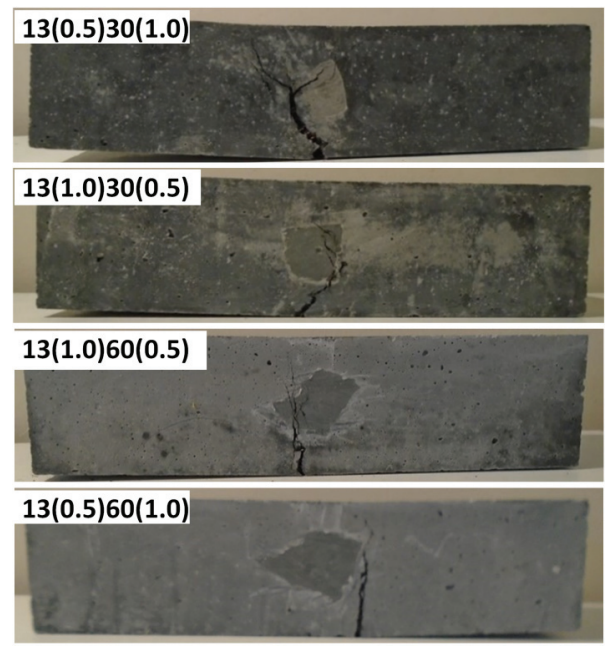

Fig. 8 - Cracking patterns of UHPFRC specimens with hybrid steel fiber

It is apparent that use of micro fiber is more successful in preventing crack formation compared to macro fibers. Similarly, as the volumetric ratio of micro fibers increases in the hybrid specimens, the first crack initiated at higher loads. It was also noted that an increase in the volume fraction governs the crack response due to the crack-bridging ability of steel fibers. After the first cracking point, a large number of closely-spaced micro cracks, which 
are not easy to see with naked eyes until the peak load, formed at the mid-span region of specimens. In all UHPFRC specimens, a major crack initiated at the point where a single crack widened due to crack localization over the half of the span. Consequently, flexural failure occurred as a result of this crack. Regardless of mono or hybrid usage, this phenomenon is distinctive for conventional fibrous concretes and it was observed from this study that the fiber content has no specific effect on this behavior. In the study, the mono and hybrid specimens' failure patterns were given for only volume fraction of $1.5 \%$ in Figures 7 and 8 , for sake of brevity.

\subsubsection{Flexural Strength, Deflection Capacity, Toughness and Residual Load Ratio}

For each test specimen, the flexural strength, toughness, peak load, as well as the deflection capacity at the peak load were determined from the load-deflection curves (Table 4). The importance of fiber type and amount on retaining load carrying capacity after the peak load was studied through the term "residual load ratio", which represents the residual capacity and strength loss on a load-deflection relationship. This ratio was calculated by dividing $P^{D}{ }_{150}$ to $P_{p}$ and was presented for all test beams in Table 4 .

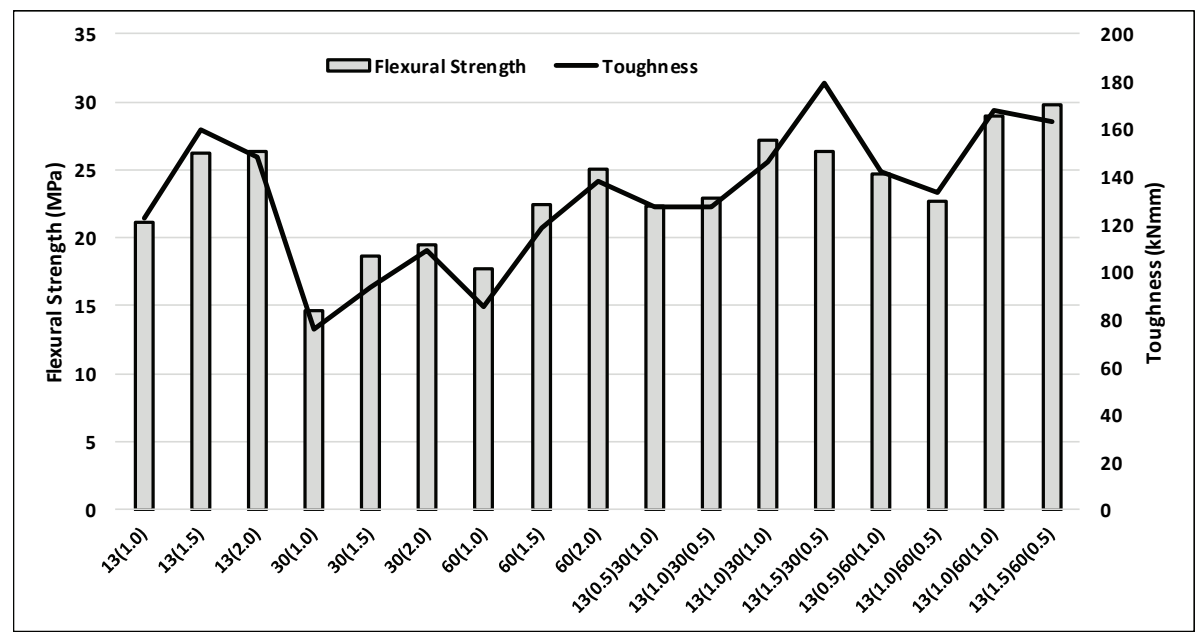

Fig. 9 - Comparison of the flexural strength and toughness performances of specimens

Table 5 - Statistical results for each volumetric fiber ratio

\begin{tabular}{ccccccc}
\hline$V_{\boldsymbol{f}}$ & \multicolumn{3}{c}{ Flexural strength } & \multicolumn{3}{c}{ Toughness } \\
\cline { 2 - 7 }$(\mathbf{\%})$ & $\begin{array}{c}\boldsymbol{\mu} \\
(\mathbf{M P a})\end{array}$ & $\boldsymbol{S t d}$ & $\boldsymbol{C o} \boldsymbol{V}$ & $\begin{array}{c}\boldsymbol{\mu} \\
(\mathbf{k N m m})\end{array}$ & $\boldsymbol{S t d}$ & $\boldsymbol{C o} \boldsymbol{V}$ \\
\hline 1.0 & 17.81 & 3.26 & 0.18 & 81 & 6.67 & 0.08 \\
1.5 & 22.87 & 2.34 & 0.10 & 129 & 15.24 & 0.12 \\
2.0 & 26.15 & 3.34 & 0.13 & 150 & 23.11 & 0.15 \\
\hline
\end{tabular}


The toughness values for all specimens were calculated using the total area under the related load-deflection curve. The variations of flexural strength and toughness values with the fiber contents are shown in Figure 9. The mean $(\mu)$, standard deviation $(S t d)$ and coefficient of variation $(\mathrm{CoV})$ were also calculated for each volume fraction (Table 5).

After conducting a series of tests, the performances related to flexural strength and toughness are discussed as follows:

- Comparing the flexural strengths of the mono and hybrid specimens to the non-fiber specimen, use of micro and macro fiber increased the strength by a range of $59 \%$ to $\% 98$ and $10 \%$ to $88 \%$, respectively. It was shown, however, that hybrid fiber use increased the strength by up to $124 \%$ depending on the fiber content.

- The toughness performances of the test specimens showed a great variety. While the toughness values of the micro fiber specimens increased by a range of 58 to 76 times compared to the non-fiber form, these changes were smaller for the macro fiber specimens (ranged from 36 to 66 times). It can be noted that use of hybrid fiber use increased these ratios by 60 to 85 times.

- The best performance among the test specimens with the mono fiber was obtained when $2.0 \%$ micro fiber was included in the UHPFRC mixture. However, the best performance from the point of macro fiber use was obtained for the steel fiber of 60 $\mathrm{mm}$. But the lowermost performance was obtained for the specimen containing the $30 \mathrm{~mm}$ macro fiber with $1.0 \%$ by volume.

- The test results showed that the best performance for the hybrid fiber specimens was obtained when the volume fraction of $2.0 \%$ was used. Among those, the specimens having the macro fiber of $60 \mathrm{~mm}$ showed, in general, better performance.

- When the hybrid fiber specimens were compared to those with macro fibers in the mono form, apparent improvements were seen on the flexural strength and toughness for all fiber contents.

- The specimens containing 1.5\% micro fiber showed better performance compared to the hybrid specimens with the same content. In contrast to this behavior, the hybrid fiber specimens (especially those containing macro fibers of $60 \mathrm{~mm}$ ) with $2.0 \%$ fiber content showed better performance compared to the micro fiber specimens.

Consequently, inclusion of micro fibers in the UHPFRC mixture resulted in better performance than the macro fibers, in terms of the flexural strength and toughness of the specimens. It was also observed that even higher values can be obtained by using hybrid fibers compared to using micro and macro fibers in the mono form.

Since first-cracking occurred at small load values, the deflection capacities of the specimens are same with the ultimate deflections on the hardening region after the cracking load. Referring to Table 4, when the performances of the specimens are evaluated in terms of their deflection capacities, the following discussions can be made.

- The best deflection capacity among the test specimens with the mono fiber was obtained when the macro steel fiber of $60 \mathrm{~mm}$ was used with the volume fraction of 
$2.0 \%$. On the other hand, the lowermost performance was obtained for the mono specimens containing $60 \mathrm{~mm}$ macro steel fibers of $1.0 \%$ by volume.

- The hybrid specimens containing the $60 \mathrm{~mm}$ macro fiber showed considerably better performance than those with $30 \mathrm{~mm}$, in terms of the deflection capacity.

In general, use of micro fiber appears to be better at increasing the deflection capacity. It was also noted that the deflection capacity improved as the fiber length in the hybrid specimens increases. This result was also well-supported by the experimental study of Ye et al. [35].

When the ultimate deflection of $L / 150$ was reached, an evident amount of strength loss could be seen on the load-deflection curve. Here, the strength loss can be expressed using the term residual load ratio. A high level of this ratio denotes small amount of strength loss for the related specimen. It also means there is a substantial capacity beyond the deflection of $L / 150$. The residual load behavior of specimens having different steel fiber contents are discussed as follows:

- While the best performance in terms of the residual capacity was achieved for the $60 \mathrm{~mm}$ macro fiber with $2.0 \%$, the specimens containing the $13 \mathrm{~mm}$ micro fiber showed more stable behavior after the peak load for all volume fractions. At the same time, the lowermost performance was obtained for the specimens containing the $60 \mathrm{~mm}$ macro fiber of $1.0 \%$ by volume.

- The hybrid fiber specimens having $60 \mathrm{~mm}$ macro fiber demonstrated much better performance than the specimens with $30 \mathrm{~mm}$. However, while the hybrid fiber specimens containing $60 \mathrm{~mm}$ macro fiber showed better performance than that of the mono form of $60 \mathrm{~mm}$ fibers of $1.5 \%$ by volume, they didn't show this improvement for the volume fraction of $2.0 \%$.

\section{CONCLUSIONS}

In the presented research paper, the flexural behavior of Ultra-High Performance Fiber Reinforced Concrete (UHPFRC) with hybrid steel fibers was investigated experimentally. Prismatic beam specimens containing mono and hybrid steel fibers were produced and tested under four-point loading in accordance with the ASTM standard C 1609. The parameters, which directly define the flexural behavior, were compared and the performances of different fiber contents were discussed. In addition, the effects of fiber content on the compressive strength and elastic modulus were evaluated. The test results with respect to the UHPFRC specimens are summarized follow:

- Regardless of mono or hybrid form, the compressive strengths of all UHPFRC specimens are much greater than that of the non-fiber specimen. It was noted that use of micro fiber is more impactful than macro fibers in relation to compressive strength. The test results also indicate that the use of different fiber types has no specific effect on the elastic modulus.

- The first cracking loads of the specimens with micro fiber were obtained as higher values in the mono fiber specimens. However, the cracking response of hybrid specimens could differ depending on the fiber contents of micro and macro fibers. 
- The best flexural performance among the test specimens was obtained for the hybrid specimens having a steel fiber of $2.0 \%$ by volume. The use of hybrid fiber in the mixture significantly improved the flexural performance of UHPFRC matrix relative to use of macro fiber. This is because the macro fibers can enhance the postpeak behavior and ductility while micro fibers improve the flexural strength and stiffness of concrete. It is important to note that the hybrid specimens including longer macro fibers showed better flexural performance. Therefore, the macro fiber of $60 \mathrm{~mm}$ provided better performance compared to that of the $30 \mathrm{~mm}$.

- Regardless of the fiber amount, use of micro fiber exhibited a more stable behavior after the peak load. The best performance in terms of the residual load capacity was achieved for the macro fiber of $60 \mathrm{~mm}$ with $2.0 \%$ by volume in mono form. It should be noted that the hybrid specimens having the $60 \mathrm{~mm}$ macro fiber showed much better performance than the hybrid specimens with $30 \mathrm{~mm}$ macro fiber.

- As a result of the use of raw materials such as $S F$ and $G G B S$, it is possible to produce UHPFRC with relatively low cement content and without the need of either special treatments or mixers. The experimental outcomes indicate that the fiber content had a significant effect on the flow ability of UHPFRC. As the fiber amount increases, the spread values decrease for all fiber types. As a result of the multiple fiber use in the mixture, the viscosity of concrete is higher than compared to fiber use in mono form. It can be deduced from the test results that the produced UHPFRC matrix is highly workable and suitable for cast in place reinforced concrete members.

\section{Acknowledgements}

The authors thank to the BEKSA-DRAMIX and the BASF companies due to their contributions in supplying materials to the study.

\section{Symbols}
b : Width of specimen
CoV : Coefficient of variation
$\boldsymbol{d} \quad$ :Depth of specimen
f : Strength
$\boldsymbol{f}_{\boldsymbol{P}} \quad$ : Flexural strength
L : Span length
$\boldsymbol{P} \quad:$ Load
$\boldsymbol{P}_{\boldsymbol{p}} \quad$ : The peak load
$P_{1} \quad$ : The first-peak load (cracking load)
$P^{D_{150}} \quad$ : The residual load at net deflection of $L / 150$ 


$\begin{array}{ll}\boldsymbol{S t d} & : \text { Standard deviation } \\ \boldsymbol{T} & : \text { Toughness } \\ \boldsymbol{t}_{\mathbf{5 0 0}} & : \text { Measure time to the first touches } 500 \mathrm{~mm} \text { diameter mark } \\ \boldsymbol{V}_{\boldsymbol{f}} & : \text { Fiber volume fraction } \\ \boldsymbol{\delta}_{\mathbf{1}} & : \text { Net deflection at the first-peak load } \\ \boldsymbol{\delta}_{\boldsymbol{P}} & : \text { Net deflection at the peak load } \\ \boldsymbol{\mu} & : \text { Mean }\end{array}$

\section{References}

[1] Brandt, A. M., Fibre Reinforced Cement-Based (FRC) Composites after Over 40 Years of Development in Building and Civil Engineering. Composite Structures, 86 1-3, 3-9, 2008.

[2] Banthia, N., Nandakumar, N., Crack Growth Resistance Hybrid Fiber Reinforced Cement Composites. Cement \& Concrete Composites, 25, 1, 3-9, 2003.

[3] Won, J. P., Hong, B. T., Choi, T. J., Lee, S. J., Kang, J. W., Flexural Behaviour of Amorphous Micro-Steel Fibre-Reinforced Cement Composites. Composite Structures, 94, 4, 1443-1449, 2012.

[4] Wille, K., Naaman, A. E., El-Tawil, S., Parra-Montesinos, G. J., Ultra-High Performance Concrete and Fiber Reinforced Concrete: Achieving Strength and Ductility without Heat Curing. Materials and Structures, 45, 3, 309-324, 2012.

[5] Kim, D. J., Park, S. H., Ryu, G. S., Koh, K. T., Comparative Flexural Behavior of Hybrid Ultra High Performance Fiber Reinforced Concrete with Different Macro Fibers. Construction and Building Materials, 25, 11, 4144-4155, 2011.

[6] Yazıc1, H., The Effect of Curing Conditions on Compressive Strength of Ultra High Strength Concrete with High Volume Mineral Admixtures. Building and Environment, 42, 5, 2083-2089, 2007.

[7] Yazıc1, H., Yiğiter, H., Karabulut, A. Ş., Baradan, B., Utilization of Fly Ash and Ground Granulated Blast Furnace Slag as an Alternative Silica Source in Reactive Powder Concrete. Fuel, 87, 12, 2401-2407, 2008.

[8] Yazıc1, H., Yardımcı, M. Y., Aydın, S., Karabulut, A. S., Mechanical Properties of Reactive Powder Concrete Containing Mineral Admixtures under Different Curing Regimes. Construction and Building Materials, 23, 3, 1223-1231, 2009.

[9] Yazıc1, H., Yardımcı, M. Y., Yiğiter, H., Aydın, S., Türkel, S., Mechanical Properties of Reactive Powder Concrete Containing High Volumes of Ground Granulated Blast Furnace Slag. Cement and Concrete Composites, 32, 8, 639-648, 2010. 
[10] Wang, C., Yang, C., Liu, F., Wan, C., Pu, X., Preparation of Ultra-High Performance Concrete with Common Technology and Materials. Cement and Concrete Composites, 34, 4, 538-544, 2012.

[11] Yang, S. L., Millard, S. G., Soutsos, M. N., Barnett, S. J., Le, T. T., Influence of Aggregate and Curing Regime on the Mechanical Properties of Ultra-High Performance Fibre Reinforced Concrete (UHPFRC). Construction and Building Materials, 23, 6, 2291-2298, 2009.

[12] Wille, K., Naaman, A. E., Parra-Montesinos, G. J., Ultra-High Performance Concrete with Compressive Strength Exceeding $150 \mathrm{MPa}(22 \mathrm{ksi})$ : A Simpler Way. ACI Materials Journal, 108, 1, 46-54, 2011.

[13] Fehling. E., Schmidt, M., Walraven, J., Leutbecher, T., Frönlich, S., Ultra-High Performance Concrete UHPC: Fundamentals, Design, Examples, Beton-Kalender. Wilhelm Ernst \& Sohn, 2014.

[14] AFGC: Recommendation: Ultra High Performance Fibre-Reinforced Concretes, Revised ed. Association Française de Génie Civil, Service D’études Techniques Des Routes et Autoroutes, 2013.

[15] JSCE: Recommendations for Design and Construction of High Performance Fiber Reinforced Cement Composites with Multiple Fine Cracks (HPFRCC), Concrete Engineering Series 82, Japan Society of Civil Engineers, 2008.

[16] JSCE: Recommendations for Design and Construction of Ultra-High Strength Fiber Reinforced Concrete Structures (Draft), JSCE Guidelines for Concrete No. 9, Japan Society of Civil Engineers, 2006.

[17] Russell, H. G., Graybeal, B. A., Ultra-High Performance Concrete: A State-of-the-Art Report for the Bridge Community, FHWA-HRT-13-060, U.S. Department of Transportation, 2013.

[18] Wille. K., Kim, D. J., Naaman, A. E., Strain-Hardening UHP-FRC with Low Fiber Contents. Materials and Structures, 44, 3, 583-598, 2011.

[19] Banthia, N., Sappakittipakorn, M., Toughness Enhancement in Steel Fiber Reinforced Concrete through Fiber Hybridization. Cement and Concrete Research, 37, 9, 13661372, 2007.

[20] Rossi, P., Antonio, A., Parant, E., Fakhri, P., Bending and Compressive Behaviors of a New Cement Composite. Cement and Concrete Research, 35, 1, 27-33, 2005.

[21] Rossi, P., High Performance Multimodal Fibre Reinforced Cement Composite (HPMFRCC): The LCPC Experience. ACI Materials Journal, 94, 6, 478-483, 1997.

[22] Rambo, D. A. S., Silva, F. D. A., Filho, R. D. T., Mechanical Behavior of Hybrid SteelFiber Self-Consolidating Concrete: Materials and Structural Aspects. Materials and Design, 54, 2-42, 2014.

[23] Sorelli, L. G., Meda, A., Plizzari, G. A., Bending and Uniaxial Tensile Tests on Concrete Reinforced with Hybrid Steel Fibers. Journal of Material in Civil Engineering, 17, 5, 519-527, 2005. 
[24] Sahmaran, M., Yaman, I. O., Hybrid Fiber Reinforced Self-Compacting Concrete with a High-Volume Coarse Fly Ash. Construction and Building Materials, 21, 1, 150-156, 2007.

[25] Akcay, B., Tasdemir, M. A., Mechanical Behaviour and Fibre Dispersion of Hybrid Steel Fibre Reinforced Self-Compacting Concrete. Construction and Building Materials, 28, 1, 287-293, 2012.

[26] Banthia, N., Gupta, R., Hybrid Fiber Reinforced Concrete (HyFRC): Fiber Synergy. Materials and Structures, 37, 10, 707-716, 2004.

[27] Nehdi, M., Ladanchuk, J. D., Fiber Synergy in Fiber-Reinforced Self-Consolidating Concrete. ACI Materials Journal, 101, 6, 508-517, 2004.

[28] Chen, Y., Qiao, P., Crack Growth Resistance of Hybrid Fiber-Reinforced Cement Matrix Composites, Journal of Aerospace Engineering. Special Issue: Mechanics of Advanced Materials and Structures, 24, 2, 154-161, 2011.

[29] Ahmed, S. F. U., Maalej, M., Paramasivam, P., Flexural Responses of Hybrid SteelPolyethylene Fiber Reinforced Cement Composites Containing High Volume Fly Ash. Construction and Building Materials, 21, 5, 1088-1097, 2007.

[30] Yao, W., Li, J., Wu, K., Mechanical Properties of Hybrid Fiber-Reinforced Concrete at Low Fiber Volume Fraction. Cement and Concrete Research, 33, 1, 27-30, 2003.

[31] Sivakumar, A., Santhanam, M., Mechanical Properties of High Strength Concrete Reinforced with Metallic and Non-Metallic Fibres. Cement and Concrete Composites, 29, 8, 603-608, 2007.

[32] Dawood, E. T., Ramli, M., Mechanical Properties of High Strength Flowing Concrete with Hybrid Fibers. Construction and Building Materials, 28, 1, 193-200, 2012.

[33] ASTM C 1609 / C 1609M-05: Structural Test Method for Flexural Performance of Fiber Reinforced Concrete (Using Beam with Third Point Loading), ASTM International, West Conshohocken, PA, 2006.

[34] Birol, T., Investigation of Flexural Behavior of Reinforced Concrete Beams with Ultra High Performance Fiber Reinforced Concrete, PhD Thesis (in Turkish), Balikesir University, Turkey, 2016.

[35] Ye, Y., Hu, S., Daio, B., Yang, S., Liu, Z., Mechanical Behavior of Ultra-High Performance Concrete Reinforced with Hybrid Different Shapes of Steel Fiber, 12th COTA International Conference of Transportation Professionals: Multimodal Transportation Systems - Convenient, Safe, Cost-Effective, Efficient, CICTP 2012, American Society of Civil Engineering, Pages 3017-3028, Beijing, China, 2012. 
